\title{
Multidisciplinary clinics - broadening the outlook of clinical learning
}

Ross Hyams*

Faye Gertner**

\section{Introduction}

Students exposed to the clinical legal education environment quickly acknowledge that clients' presentation of their legal problems is much more complicated, subtle and multifaceted than they could ever have believed was possible. They regularly report to their clinical supervisors that their classroom experience has not adequately provided them with either the practical skills or legal knowledge that they need in order to deal confidently and competently with the many factors and complexities underlying clients' legal problems. They report feelings of inadequacy in their dealings with issues that often form a deep-rooted subtext to clients' legal problems. These issues may be a mixture of psychiatric, financial, social, educational and ethnic or language factors.

In recognition of this inadequacy reported by clinical students, this paper focuses on the necessity of developing multidisciplinary legal clinics - law students working in a clinic together with students from other disciplines, such as social work, financial counselling and psychology. Professionals across a wide range of fields have increasingly recognised the advantages of multidisciplinary practice in teaching, scholarship and service delivery to clients ${ }^{1}$. A multidisciplinary approach to legal practice is becoming more relevant as legal systems change ${ }^{2}$ to encompass processes and procedures of justice delivery which deviate from the traditional adversarial paradigm.

The aim of this paper is to investigate the challenges of establishing and working in such a clinic.

* Senior Lecturer, Monash University

** Director Monash Oakleigh Legal Practice, Monash University

1 See Schlossberg D "Promoting Justice Through Interdisciplinary Teaching, Practice, And Scholarship: An Examination Of Transactional Law Clinics In Interdisciplinary Education" (2003) 11 Washington University Journal of Law and Policy 195; Green B "Reflections On The Ethics Of Legal Academics: Law Schools As MDPs: Or, Should Law Professors Practice What They Teach? (2001) 42 S. Texas Law Review 301; Kritzer H " The Professions Are Dead, Long Live The Professions: Legal Practice In A Post-Professional World” (1999) 33 Law And Society Review 713

2 Potter D, "Lawyer, Social Worker, Psychologist and More: The Role of the Defence Lawyer in Therapeutic Jurisprudence" (2006) Elaw- Murdoch University Electronic Journal of Law Special Series 95. 
Other writers have explored the integrated service model ${ }^{3}$ in which clients can be referred from a community legal service to aligned services, often co-located in the same building. ${ }^{4}$ However, such a service model is not a multidisciplinary environment. This paper will explore the perceived educational benefits to students of working in a genuine multidisciplinary environment, including exposure to a social justice agenda which, the writers contend, is currently lacking in legal education. Further, it will consider the perceived tension between the orientation of lawyers as "zealous advocates" and other caring professions. Finally, the paper will look at the practical aspects of forging effective alliances between organisations in order to create the appropriate environment for a multi-disciplinary legal clinic, including issues of resourcing. The paper will conclude that, despite the ideological and practical issues which need to be resolved in order to create an effective multidisciplinary clinic, law students would derive great benefit from involvement in such a clinic.

\section{Why change clinical practices?}

In order to maintain relevance, clinical legal education needs to teach about practices and processes that are going on "out there" in the legal system. It is clinicians' responsibility to ensure that legal clinics provide students with educational opportunities which will best enable them to take their place in the workforce. It has been long accepted that lawyers require an understanding of how to perform in teams within the legal profession. ${ }^{5}$ However, there is also a burgeoning understanding that lawyers need to develop skills in working in multidisciplinary environments, as team members with non-lawyers such as social workers, psychologists, financial planners, interpreters and other professionals ${ }^{6}$. Currently, many clinical legal education units embrace the notion of "student teaming"7 but it is rare to find student legal teams which encompass students from other disciplines, working together in a clinic.

There is no doubt that the call for multidisciplinary clinical legal education is a timely one. In Australia, initiatives such as Drug Courts necessitate lawyers working in a new non-adversarial environment, together with prosecutors, psychologists, therapists, support workers and other court officials in order to secure a therapeutic outcome for the defendant. ${ }^{8}$ Indigenous sentencing courts around Australia require lawyers to work, often in a roundtable environment, with a magistrate, an Aboriginal Elder, the defendant's support people and indigenous court support

3 See Noone M "Towards an integrated service response to the link between legal and health issues" (2009) 15 Australian Journal of Primary Health 203; Clarke S \& Forrell S (2007) "Pathways To Justice: The Role Of NonLegal Services. Justice issues" Law And Justice Foundation of NSW: Sydney; Curran L “ Making Connections: The Benefits Of Working Holistically To Resolve People's Legal Problems (2005) E law -- Murdoch University Journal of Law 12

4 Springvale Monash Legal Service, operating since 1975 as a joint venture in clinical legal education with Monash University, Melbourne, is very successfully co-located with the Springvale Community Aid And Advice Bureau.

5 See Chavkin D (2002) Clinical Legal Education: A Textbook For Law School Clinical Programs. Chapter 9 Collaboration.

6 King M, Freiberg A, Batagol B, Hyams R (2009) Non-Adversarial Justice, The Federation Press at 238.

7 Evans A \& Hyams R, "Independent Evaluations of Clinical Legal Education Programs: Appropriate Objectives and Processes in an Australian Setting” (2008) 17 Griffith LR 52 at 72.

8 Moore D (2007) 'Translating Justice and Therapy: The Drug Treatment Court Networks' 47 British Journal of Criminology 42 at 48 . 
workers. ${ }^{9}$ These modes of hearing are no longer pilot programs or idiosyncratic initiatives, but are becoming an integral part of the Australian legal system, as are many other types of problem-solving courts such as mental health courts, family violence courts, alcohol courts and neighbourhood justice centres. ${ }^{10}$ All these courts have processes and requirements of teamwork which are a far cry from the traditional adversarial paradigm that law students are usually exposed to in their legal education.

Thus, clinicians need to acknowledge that the current style of clinical legal education does not prepare students very well for working in a multidisciplinary team environment. Students need to understand the language and philosophy of professionals in other disciplines; they need to have at least a rudimentary understanding of the fundamentals of other disciplines in which lawyers regularly intersect and interact. ${ }^{11}$ It is exceedingly rare that a client of a legal clinic presents with a problem that can be defined strictly as "legal" only - more often than not, clients' legal problems are combined with a myriad of social, financial, psychological and other issues. Often, despite lack of training, clinical supervisors are able to identify these issues and refer clients to appropriate professionals. Whether clinic students have the skills to do this is debatable. Clinicians need to acknowledge that legal knowledge does not have hegemony over the resolution of clients' problems and that other professionals can assist towards a positive resolution of the issues that clinical clients present. Further, both clinicians and law students need to resile from the "superior" status that they give the legal system and accept that clients' problems may be better resolved by taking a multidisciplinary and holistic approach.

\section{Educational Benefits of Collaboration in a Specialist Clinic}

The majority of writings on multidisciplinary clinics relate to specialist clinics. ${ }^{12}$ These clinics involve law students working with students from other disciplines - usually from the social sciences, in clinics that deal with domestic violence, children's interests and criminal defence. ${ }^{13}$ St Joan ${ }^{14}$ refers to the educational benefits of collaboration and the influence of social sciences to inform clinical legal education, specifically in the context of the domestic violence specialist clinic known as The Domestic Violence Civil Justice Project (DVCJP) established by the University of Denver College of Law. Having referenced the many writings by academics and clinical practitioners, she distils the essence of the influence of the social sciences on clinical legal education to include -

- $\quad$ strengthening the development of case theories;

9 Marchetti M \& Daly K (2007) "Indigenous Sentencing Courts: Towards a Theoretical and Jurisprudential Model" 29 Sydney Law Review 415 at 421.

10 King et al, n 6 .

11 Id.

12 See Schlossberg D “An Examination of Transactional Law Clinics and Interdisciplinary Education “ (2003) 11 Washington University Journal of Law $\mathcal{E}$ Policy 195; Benson S "Beyond Protective Orders: Interdisciplinary Domestic Violence Clinics Facilitate Social Change" 14 Cardozo J. L. Eु Gender 1; Bratt C "Beyond The Law School Classroom And Clinic - A Multidisciplinary Approach To Legal Education” 13 New Eng. L. Rev. 200 1977-1978; Enos V \& Kanter L “Who's listening? Introducing Students to Client-Centred, Client-Empowering, and Multidisciplinary Problem-Solving In A Clinical Setting” 9 Clinical L. Rev. 83 2002-2003.

13 St Joan J "Building Bridges, Building Walls: Collaboration between Lawyers and Social Workers in a Domestic Violence Clinic and Issues of Client Confidentiality" (2000-2001) 7 Clinical L Review 403 at 415.

14 Id. 
- appreciating and enhancing the psychological dynamics of the lawyer-client relationship, and - modelling effective interviewing and counselling skills. ${ }^{15}$

The impact of this influence can be seen when a multidisciplinary clinic attempts to explain and understand its role and function in relation to clients and to the students who work together to provide services to the clients. One of the fundamental concerns when establishing a multidisciplinary clinic is to ensure that it serves its purposes, which must be clearly defined and understood by all participants, including the students and supervisors. Where quality service delivery to clients and long term educational benefits to all students involved are two of the goals, the multidisciplinary clinic must develop and implement a rigorous and effective training program to achieve the outcomes sought.

The study of law does not guarantee students a particular perspective or understanding about social justice and certainly does not usually deal in the social sciences. The training provided to students at a multidisciplinary clinic needs to be specialised in subject matter and skills as well as philosophically relevant. The pedagogical underpinnings of the Domestic Violence multidisciplinary clinic described by St. Joan firstly involved the provision of information (about Domestic Violence) to students. Professional skills and interdisciplinary collaboration are also taught during an intense orientation period and throughout the students' time at the clinic. In addition, case reviews with the students occurred regularly. Students were provided with written materials, but the focus was on discussion and reflection. ${ }^{16}$ The role of specialised training that evaluates processes and methods of collaboration in addition to the training of students in traditional lawyering skills ensures that students are encouraged to reflect and provide input. Specialised training in collaborative processes itself has tangible pedagogical benefits for students.

St Joan identifies two distinct styles of collaboration that emerged which she describes as "sideby-side" and "hand-on-hand" styles. The first involves the law and social work students working separately on different matters for the one client. The second style involves the students working together at the same time and place on the same or different issues for the one client. Research showed that most students drew from both styles depending on their need at a particular time.17

The "side-by-side' style enabled students to be more efficient and effective with their time and enabled law students to work separately or together with social work students as required - however there was always the risk of "triangulation" where the client is part of a three-way relationship. ${ }^{18}$ This is less likely to occur in the "hand-in-hand" style.

The flexibility afforded by collaboration is evidenced by the fluidity of adapting and adopting the different styles of collaboration at different times in attempting to fulfil different needs. Allowing students to work matters out for themselves allows them to develop a style of working with others that best suits their personality and interpretation of their respective roles. However, supervisors having provided clear guidance and ongoing training as to the expectations and framework of the clinic ensures that students are clear about their boundaries and the goals and aims of the multidisciplinary clinic.

15 Ibid at 405 .

16 Ibid at 418 .

17 Ibid at 417 .

18 Ibid at 418-419. 
The importance of clear boundaries from a pedagogical perspective is that the multidisciplinary clinic has an established and apparent framework for its operation. However, there must be sufficient flexibility within it to provide guidance to students and supervisors whilst also enabling students to engage in ways that is most meaningful for them individually - ultimately this ensures the maximum benefit for the client. From a pedagogical viewpoint, students being encouraged to participate in, reflect upon and contribute to the methodology and operating systems of a clinical framework with a sound educational objective would serve to only enhance their experience.

In St. Joan's paper, students identified various benefits of collaboration, including provision of improved client services; a broadened student perspective; and the advantage of sharing the experience of caring about a client. ${ }^{19}$ Social work students stated that they had helped the law students deal with their emotional needs and that they had learnt more about the law and the legal system. ${ }^{20}$ The social work students also indicated that they felt there was a power imbalance in favour of the law student at times. St Joan explains that, as the clinic is primarily a law clinic, clients generally perceive lawyers as being more authoritative than social workers and that lawyers are seen to be more devoted to the client's case than a social worker. ${ }^{21}$ These matters go to the very core of the issues that underlie multidisciplinary clinics. Changing a client's perception of different professionals and their role will alter only with their own individual experience. Social worker and law students' perceptions and understanding of each other and the role that they each play in relation to a particular client will be reinforced or re-evaluated based on experience. This is augmented by formal teaching and a developing understanding (based on knowledge) of the other's role and guiding philosophy.

\section{The Social Justice Agenda}

For law students, there is much more to be gained from multidisciplinary practice than the mere acquisition of multifaceted skills. Working in a multidisciplinary team exposes law students to a social justice agenda which is enriched by their participation and interaction with students and professionals of other disciplines. It is rare for law students, within the context of a classroom, to be taught to both question and practise law within a broader social justice framework. Legal clinics provide law students with the opportunity to place law in its social milieu and multidisciplinary clinics expand the opportunities for students to perceive law in a much broader social context. The myriad of factors (social, financial, psychological and the like) which lead clinic clients to experience legal problems are often implicit in the way a client presents to legal clinic. Multidisciplinary practice makes these factors explicit.

Rand ${ }^{22}$ believes that law students' concept of social justice must not occur as a by-product of their exposure to clients, but must be "strongly held and operational." $23 \mathrm{He}$ complains that the US Model Rules of Professional Conduct does not provide enough guidance as to concepts inherent in

19 Ibid at 420 .

20 Ibid at 421.

21 Ibid at 422.

22 Rand S "Teaching Law Students to Practice Social Justice: an Interdisciplinary Search for Help through Social Work's Empowerment Approach" (2006) 13 Clinical Law Review 459

23 Ibid at 463. 
social justice. ${ }^{24}$ This complaint is echoed by Aiken and Wizner in their comment that there are no ethical or professional rules governing lawyers' ability to simply possess adequate professional skills when dealing with clients, except a very general rule requiring lawyers to be "competent". ${ }^{25}$ Certainly the same can be said of the rules governing professional interactions within Australia. In Victoria (the writers' jurisdiction) the most recent professional conduct rules ${ }^{26}$ require practitioners to serve their clients "honestly and fairly, and with competence and diligence", ${ }^{27}$ but this is as far as the Rules take any concept relating to the pursuit of social justice or fairness. Accordingly, it is difficult for law students to evolve a social justice agenda in their understanding of law, as often the social justice perspective is not made explicit in classroom studies and will only be implicit in their dealings with clients in a clinical environment. The same may be said of practitioners - if they have had no exposure to social justice issues during their legal education and professional conduct rules provide no further guidance, it is difficult to imagine that a social justice perspective to their legal work will simply emerge out of nowhere.

It may be argued that is not necessary for lawyers to approach their professional role with a social justice perspective. Even if one accepts this contention, the fact still remains that a lawyer working in a multidisciplinary environment is at the very least required to understand the professional mindset of the other disciplines (such as social work) who see their professional responsibilities as including a social justice agenda. Considering the increasing requirements on lawyers to work in collaborative teams and non-adversarial environments, which require an understanding of other professionals' perspectives and skills, the fact that both law students and lawyers receive little or no direction as to social justice issues does not augur well for lawyers' ability to operate professionally and competently in the future.

If, as Anderson, Barenberg and Tremblay contend, both social workers and lawyers "strive to hold fundamental society values and promote public service" 28 then law students have much of value to learn from working with other disciplines such as social work. There is a strong social justice and client empowerment tradition in social work studies going back at least a century ${ }^{29}$ which can enrich law students' interactions with their clinic clients. Obviously, there are tensions between social workers' broader social agenda understanding of their role with clients compared to the traditional notion of lawyers as zealous advocates, which will be discussed in the next section of this paper. However, despite perceived ideological differences between the two disciplines (which the writers of this paper believe can be quite adequately resolved) interdisciplinary collaborations between social work and law students have shown that the law students' interactions with their clients become more nuanced, subtle and comprehensive because of their interactions, observations and modelling of social work students' approaches to clients. ${ }^{30}$

24 Ibid at 473.

25 Aiken J \& Wizner S “This Isn't Law, It's Social Work” (2003) 11 Washington University Journal of Law and Policy 63 at 66.

26 Professional Conduct and Practice Rules 2005 (Vic).

27 Ibid Rule 2.1.

28 See Anderson A, Barenberg L \& Tremblay P "Professional Ethics in Interdisciplinary Collaboratives: Zeal, Paternalism and Mandated Reporting” (2006 - 2007) 13 Clinical Law Review 659 at 665.

29 Rand, n22 at 480.

30 Anderson et al, n28 at 689. 


\section{Tension between Orientations of Lawyers and Other Professionals}

Whilst there is no doubt that members of different disciplines - law and social work - want to work in the best interest of their clients, how this is achieved will vary. The underlying philosophies and professional rules that govern each profession will at times come into conflict, especially in a multidisciplinary context. How these differing approaches can be reconciled is one of the challenges facing multidisciplinary clinic students and supervisors alike.

It may be that the tension of competing and sometime inconsistent focuses of the different disciplines can cause disruption to the provision of quality service to clients. In an educational setting, however it can also provide the opportunity to explore the reasons for the disparity between the two professions and the possible alternatives to resolve the differences, whilst at the same time improving each discipline's understanding of themselves and each other.

Anderson et al acknowledge that interdisciplinary collaboration by social workers with lawyers provides lawyers with skills that will enhance their ability to provide a quality service to their clients. ${ }^{31}$ They also raise the question of the impact of the different orientations of lawyers, who typically are zealous advocates for their clients and social workers - who attend to the larger moral community and social justice concerns. ${ }^{32}$

The issue is whether a lawyer's zealous advocacy for their client, when working with a social worker, is diluted. The question which must be answered is whether a lawyer's zealous advocacy decreases when confronted with the broader community orientation of a social worker, especially when working together in an interdisciplinary clinic. What impact or conflicts do the two disciplines' ethical/professional rules face in situations where there is multidisciplinary collaboration?

Whilst we may be tempted to focus on "zealous advocacy" seemingly as the only position for lawyers to adopt, Parker \& Evans posit the view that there is more than one ethical position for lawyers to adopt. ${ }^{33}$ These positions include the moral activist view where the lawyer's role is to do "good" because it is the right thing to do in the greater interests of social and political justice and relational lawyers who integrate their personal ethics with legal practice and present an outlook that might be considered more holistic. ${ }^{34}$ In the context of a multi-disciplinary clinic these alternate views of a lawyer's "ethical" position and the impact it may have on practice and interactions with members of other disciplines may well inform tensions and ways to resolve them, should they become apparent. Many US writers take their starting position as the Model Rules of the profession, ${ }^{35}$ whilst Parker and Evans challenge us to go beyond the professional rules of practice in our perception of lawyering and its ethical intersections.

Anderson et al's position is that the focus on "conflict" between the professions is overstated; rather that collaboration provides an opportunity for the client's goals and options to be fully

$31 \quad$ Ibid at 661.

32 Ibid at 663.

33 Parker C \& Evans A (2007) Inside Lawyers' Ethics, Cambridge University Press, Port Melbourne at 37

34 Id.

35 For example, Rand n22. 
explored by their lawyer through legal means and through "zealous advocacy with third parties" 36 . This position does not appear to sit easily with St Joan's styles of collaboration - where the social work and law students are more like "partners" than one practitioner who accesses other disciplines on an "as needs" basis.

There are similarities and differences between the disciplines that will create a pull and push situation in a multidisciplinary clinic. Both social work and law are professions that strive to help their client, at times in similar ways - advocating, advising and facilitating resolution. Shared values are apparent ${ }^{37}$ yet there are distinctions and tensions which are also are important. The professional orientation and focus of the two disciplines provide the potential friction, which is neatly summed up by Galowitz:

There is an inherent tension between a lawyer's and a social worker's ethical responsibilities. The lawyer's responsibility is to advocate zealously for the client's wishes, while the social worker's is to safeguard the client's best interests. ${ }^{38}$

Accordingly, as Galowitz points out ${ }^{39}$ that tension may emerge in relation to the different disciplines' approach to clients' instructions. Lawyers usually see their responsibilities towards clients instructions quite clearly - providing advice and guidance and then being bound by the client's instructions, regardless of whether the individual lawyer believes those instructions to be in the best interests of the client or not. By comparison, social workers will generally look at clients' issues more holistically ${ }^{40}$ and will often see their involvement in terms of an "intervention" in an attempt to resolve issues in the best interests of the client. Stanger uses the example of child delinquency proceedings. ${ }^{41}$ She opines that social workers would approach the matter with an attempt to determine the problem in the best interests of the child, family and the community, ${ }^{42}$ whereas traditionally a lawyer would see their role as advocating specifically from the instructions of the client. Despite this, where detailed guidelines and protocols are put into place to assist both supervisors and students in dealing with the client and each other, the tensions between the disciplines, as well as any impact on clients, can be minimised. Ongoing dialogue, both informal and formal, between the students and supervisors, case reviews and detailed orientation and training are all tools that can be used to acknowledge and understand the competing and sometimes inconsistent approaches and aims of the two disciplines.

It is unrealistic to ignore the tension that might arise between disciplines of a multidisciplinary practice, but it is also not helpful to overplay it. Rather, any friction in the way the disciplines approach mutual clients should be acknowledged and energy directed towards striving to work within those differences. Resolving differences and overcoming any professional tensions can be achieved by the mutual understanding of one another's professional roles and expectations

\footnotetext{
36 Anderson n28 at 665 .

37 Id

38 Galowitz P "Collaboration Between Lawyers and Social Workers: Re-examining the Nature and Potential of the Relationship of the Relationship" (1999) 67 Fordham L Rev 2123 at 2140

39 Ibid at 2141.

40 Peters J “ Concrete Strategies For Managing Ethnically Based Conflicts Between Children's Lawyers And Consulting Social Workers Who Serve The Same Client” (1991) Kentucky Children's Rights Journal 15.

41 Stanger L "Conflicts Between Attorneys And Social Workers Representing Children In Delinquency Proceedings" (1996) 65 Fordham Law Review 1123

42 Ibid at 1125.
} 
from those roles, having clear policies and protocols in place and ensuring that there is open communication. ${ }^{43}$ This is the key beyond any other factor. The issue of whether law students lose their "zealousness" and begin to view their professional role more holistically as a result of working with social workers or whether social workers lose their broader perspective of an issue can become minor compared to the possibility of poor or confused service delivery - which has the potential to completely undermine any attempts at a successfully functioning interdisciplinary clinic.

Anderson et al pose the question of whether lawyers will be "tainted" and therefore less able to properly undertake their obligations and responsibilities as lawyers, if they adopt the social workers' approach of 'what is in the best interests of the client' as opposed to ensuring that a client's decision is fully respected. ${ }^{44}$ Ultimately, based on their experiences in the interdisciplinary clinic, the authors conclude that this is not likely to happen. In fact, the lawyers were able to synthesize various approaches and without compromising their fundamental obligation to the client, were able to provide their clients with more layered and informed assistance in the client making their decisions on how to proceed in their matters. ${ }^{45}$

Much published work that considers interdisciplinary clinics focus on those combining lawyers and social workers ${ }^{46}$, but one of the most influential writings on multidisciplinarity in clinical legal education by Schlossberg examines an interdisciplinary clinic with a small business and law focus. ${ }^{47}$ A number of interesting concerns unique to small business, as compared to social worker, matters are discussed. Schlossberg gives consideration to the educational aspect of clinics for the students involved. She emphasises the differences in culture and training between different disciplines and points out that in successful social justice collaboration, emphasis must be placed on group dynamics, the value of listening and mutual respect. She also acknowledges that there is a perception that law students are arrogant and that this will impact in their dealings with other disciplines. ${ }^{48}$

Some of the tensions that exist between disciplines can be explained by the difference in training and emphasis on preparation for work. Whilst it may be trite to state that law schools traditionally only teach law, there is generally little focus on practical skills whilst in business school an obvious feature is the preparedness of students for working in their chosen field. ${ }^{49}$

Accordingly, it is important to acknowledge that underlying tensions between disciplines may always be a characteristic of multidisciplinary clinics. What is important is the acknowledgment that such tensions exist and why - which means consideration must be given to the background

43 Anderson $n 28$ at 667-668.

44 Ibid at 679 .

45 Ibid at 689 .

46 See Galowitz P "Collaboration Between Lawyers and Social Workers: Re-examining the Nature and Potential of the Relationship of the Relationship" (1999) 67 Fordham L Rev 2123; Zawisza C \& Beckerman A "Two Heads Are Better Than One: The Case-Based Rationale For Dual Disciplinary Teaching In Child Advocacy Clinics" 7 Fl. Coastal L. Rev. 631; Faller K \& Vandervort F "Interdisciplinary Clinical Teaching Of Child Welfare Practice To Law And Social Work Students: When World Views Collide" 41 U. Mich. J. L. Reform 121 2007-2008.

47 Schlossberg D "An Examination of Transactional Law Clinics and Interdisciplinary Education" (2003) 11 Washington University Journal of Law \& Policy 195 at 212.

48 Ibid at 214.

49 Ibid at 216. 
and theories underlying each of the disciplines, understanding and respecting each other's viewpoint and contribution in achieving an outcome for a client, and having a system in place that encourages discussion and collaboration in developing solutions to problems that emerge.

\section{Forging an Effective Alliance between Organisations}

Whilst there are different models for collaborative clinics, the question of how to best ensure a co-operative and effective clinic essentially relies on several key points. According to Eckel and Hartley, ${ }^{50}$ the main challenges for collaboration are for the participants to reconcile organisational goals and to develop clear and compatible expectations. Central to this is the need to address the participants' disparate sets of values and assumptions and to ensure that there is, at least, respect for the each participant's viewpoint. ${ }^{51}$ At a practical level, the parties to the joint effort need to regularise processes and procedures and to understand and reconcile their own and their collaborating parties' set of norms and expectations. ${ }^{52}$

When forming partnerships in a collaborative environment, the parties must develop a common set of rules which are derived from each party's previously formulated rules. This set of rules must be embraced by both parties through negotiation. Further, new rules must be created that will deal with new situations that come up as a result of the collaboration. ${ }^{53}$

Eckel and Hartley's basic premise is that where parties (usually organisations) come together in a collaborative fashion, they have chosen each other because they share common ambitions and objectives. There is recognition of the inherent tensions between the interests of the individual partners and as a collective. There is a personal commitment between the participants based on face to face interaction rather than strict adherence to policy and protocols, based on mutual trust and respect and a sense of common purpose. Finally, there is the capacity and desire to establish a "shared identity" which reduces the chance for conflict and misunderstanding. ${ }^{54}$

There are a variety of models for collaborative and interdisciplinary clinics and different names given to them - interdisciplinary collaborative, ${ }^{55}$ curricular joint ventures $(\mathrm{CJV}),{ }^{56}$ interdisciplinary clinic, ${ }^{57}$ interdisciplinary or multi-professional collaborations in transactional law clinics ${ }^{58}$ or multi-disciplinary practices, ${ }^{59}$ all of which have their own meaning as ascribed to them by the authors. Despite the varying nomenclature, they all struggle with similar issues in resolving the differences and tensions between the participating parties and in creating structures and rules that better equip that venture to work effectively towards the aim of providing valuable experience to

50 Eckel P \& Hartley H "Developing Academic Strategic Alliances: reconciling multiple institutional cultures, policies and practices" (November/December 2008) The Journal of Higher Education Vol 79 No. 6, 613.

51 Ibid at 615.

52 Ibid at 616. For a definition of organisational culture see 616.

53 Ibid at 617.

54 Ibid at 632 .

55 Anderson n28.

56 Eckel n50.

57 See St Joan n13.

58 See Schlossberg n47.

59 Trubek L \& Farnham J "Social Justice Collaboratives: Multi-disciplinary practice for people” 7 Clinical L Review 2000-2001. 
the students and an improved service to the clients.

Amey and Brown ${ }^{60}$ put forward the proposition that interdisciplinary collaborations work through three stages to achieve collective thinking on behalf of the participants. Based on a case study conducted over a period of 18 months, the authors examined the creation and development of an interdisciplinary team and examined strategies, leadership, resolution of differences and conflict and setting of goals. ${ }^{61}$

The initial stage of the interdisciplinary collaboration was identified by the participants (as a group) functioning and thinking independently. Each group put forward its own view as the dominant one and the leadership was traditional in the sense that it was leadership from the top down. ${ }^{62}$

The second stage was marked by the groups reaching an agreement and understanding of some of the goals and values and being more able to work parallel with one another. It also found groups, (whilst still sticking to their disciplines) more able to acknowledge the importance and contributions of the work being done by each other. The nature of the leadership altered as was demonstrated by being more facilitative and inclusive in style. ${ }^{63}$

The third stage, which the authors note was never completely achieved, would be evidenced by the groups acting as a collective and the ideas and implementation of those ideas being shared by all members. The collective would be dominant in the mindset of the participants. The interaction and dialogue would lead to new knowledge, ideas and solutions being devised and implemented, leading to fundamental change. At this third stage, challenges would only serve to make the members of the collaborative work better together through listening, learning and reflection. ${ }^{64}$

The essence of a successful alliance appears to lie in a range of factors, including the nature and philosophies of the parties concerned. Values and goals need to be well communicated and shared amongst all disciplines involved in the collaboration. There needs to be the capacity to make and adapt to rules and the desire and ability to evolve together, striving to achieve particular goals. Any alliance will not be without issues that need resolution, but the best path to success will necessarily require the parties to participate with a maturity that enables them to change and grow, without it being perceived as a weakness or defect when changes are made.

\section{Resourcing Issues}

There is no doubt that the costs of establishing any form of clinical program will be very substantial, even prohibitive. The simple start-up costs of a clinic that operates on a two days per week basis may be in excess of AUS $\$ 100,000$. There is then the ongoing commitment to both administrative and professional salaries, in addition to the myriad of outgoings required to maintain a legal office. Even if there is a solid clinical infrastructure already existing, there will be costs associated with expanding clinical programs to enable a multidisciplinary practice to function effectively. We would not be the first to point out that law school deans are often not

60 Amey M and Brown D "Interdisciplinary Collaboration And Academic Work: A Case Study Of The University - Community Partnership (Summer 2005) New Directions For Teaching And Learning (102) 23.

61 Ibid at 24.

62 Ibid at 25-26.

63 Ibid at 28 .

64 Ibid at $28-29$. 
particularly encouraging of clinical expansion, ${ }^{65}$ but as Evans and Hyams note, there will be many collateral outcomes of clinical programs that are especially apposite in a multidisciplinary practice - for example, research and teaching collaborations which emerge from the clinic, the increase in student satisfaction across a number of University faculties and the benefit to the University of increased benevolent interactions with the community. ${ }^{66}$

However, as Schlossberg ${ }^{67}$ points out, because most academic departments or faculties are quasi independent institutions within their University, this leads to competition for limited resources and does not encourage multidisciplinary collaboration. Further, questions arise as to which faculty or department should bear the brunt of sustainability. These are issues that need to be resolved before the doors open to the first client and cannot be left to be resolved "on the run".

An underutilised resource, certainly in Australia, is University alumni. Whilst approaching alumni for donations towards particular clinical projects may be appropriate, it is not a strategy that will ensure long-term sustainability of the multidisciplinary clinic. Rather, alumni can be a great source of wisdom, knowledge and ideas and may also be of great assistance in making connections with appropriate funders. Accordingly, it may be appropriate to establish a multidisciplinary clinical advisory board with members being alumni of the various University faculties involved in providing direction and support for the multidisciplinary clinic. In this regard, the clinic creates a stakeholder network ${ }^{68}$ which can be called upon to provide assistance in a multitude of ways with the ongoing sustainability of the clinic. As there are various faculties involved, it would be possible to draw upon a multitude of disciplines and potential funders by establishing such a stakeholder group. Arguably, the ongoing sustainability of a multidisciplinary clinic may rely on the existence of such a group, especially if there is an external review process in place which may seek to evaluate the clinic simply on the basis of resource or cost implications. If such an evaluation is imposed upon the clinic, the ability to call upon an established alumni network for support and direction would be invaluable. This has certainly been implemented in the past with great success in established clinics. ${ }^{69}$

\section{The way forward}

The clinical team of the faculty of Law, Monash University in Melbourne, Australia has formulated and commenced the implementation of a research project relating to the development of a multidisciplinary clinic. The clinic has both a service orientation and a research objective. The aim is to research whether students receive a better quality education when involved in a multidisciplinary clinic. The research will attempt to clarify whether there is a measureable difference between single service as opposed to multi-service delivery. As far as we understand, in Australia it has not yet been researched (from a law faculty perspective) as to how a legal clinic can deliver more effective legal and social services. The pilot project has been created in conjunction with other stakeholders within the University (the schools of Medicine, Business and Economics, Arts, Social Work) who are also part of the multidisciplinary clinic pilot program at Monash

65 Evans and Hyams, n7 at 59.

66 Ibid at 60.

67 Schlossberg n47 at 212.

68 Evans and Hyams, n7 at 79.

69 Id. 
Oakleigh Legal Service, a well-established legal clinic which has been in operation in conjunction with the Faculty of Law since 1979.

It is anticipated that a successful research funding grant will enable the clinical team to conduct empirical research as to the efficacy of multidisciplinary service delivery on pedagogical objectives - that is, whether there are benefits to students of a combined legal/social orientation to the acquisition of lawyering skills. Further, the research aims to determine the challenges to pedagogy encountered by teachers involved in the multidisciplinary clinic and to discover how these challenges might be resolved. In this way, a multidisciplinary clinic has been established without an initial exorbitant financial outlay, as it is drawing upon a 30 year established infrastructure which only has to make minor alterations to its practices and procedures in order to enable a pilot multidisciplinary practice to commence. As such, this is a low-risk method of piloting the concept which can involve discovering the difficulties and/or benefits associated with multidisciplinary practice and resolving them, prior to committing large resources to establish and sustain a purpose-built clinic.

Based on the results gained from the pilot project and as part of the Monash University Faculty of Law long term vision, it is hoped ultimately to establish a new Integrated Clinical Services Suite $^{70}$. This would be presided over by the Faculty of Law as a permanent multidisciplinary clinical practice and would provide a holistic legal, medical and financial-related advice service to low income clients. Clinical services would be delivered through supervised later-year students of the Faculties of Law, Medicine, Business and Economics and Arts, with services made available to non-English speaking clients/patients through a partnership with students studying language translation and interpretation. By focusing on assisting low income clients/patients and meeting their needs in a fully coordinated manner, academic staff and students involved in the practice would deliver 'whole of person' services to the community on a permanent basis.

\section{Conclusion}

Legal educators ignore the changing landscape of the legal system to their students' peril. The need to understand team work and to function professionally in a multidisciplinary environment is an essential skill for today's law graduates. As discussed above, there are a number of issues, both ideological and practical, which require resolution in order to establish and maintain an effective multidisciplinary service. These issues are not insurmountable, but they require identification and open communication in order to resolve them.

The writers maintain a robust belief that law students will derive educational advantage from participating in a multidisciplinary setting. However, direct empirical evidence is needed to put that belief to the test. Our expectation is that the Monash University Faculty of Law multidisciplinary clinic pilot project will provide the data to demonstrate the pedagogical value of students incorporating multidisciplinary ideologies and practices in their clinical work. If results are positive, as expected, we would hope to make multidisciplinary practice in clinical legal education the rule, rather than the exception. These changes are timely, given the transformations

70 Idea proposed by Dr. Adrian Evans, Associate Professor, Faculty Of Law, Monash University 
in ideology and practice being experienced over recent years in the Australian legal system. These changes are also necessary in order for law graduates to be better equipped to practise effectively in a changing legal environment. 